\title{
Pre-Operative Measurement of the Morphometry and Angles of the Anterior Clinoid Process (ACP) for Aneurysm Surgery
}

\author{
Medición Preoperatoria de la Morfometría y los Ángulos del \\ Proceso Clinoide Anterior (PCA) para la Cirugía de Aneurisma
}

Aycicek Cecen"; Erhan Celikoglu**; Merih Is**; Aysin Cetiner Kale ${ }^{* * * *} \&$ Basak Torum Eroglu****

CECEN, A.; CELIKoglu, E.; IS, M.; CETINER KALE, A. \& TORUM EROGLU, B. Pre-operative measurement of the morphometry and angles of the anterior clinoid process (ACP) for aneurysm surgery. Int. J. Morphol., 34(4):1333-1338, 2016.

SUMMARY: The anterior clinoid process (ACP) is proximal to vital structures, such as the optic nerve, internal carotid artery and ophthalmic artery; therefore, study of its anatomy is important in guiding and defining surgery. We studied the anatomical structure of the ACP, including the angle formed by the apex of the ACP triangle, and its orientation, to provide information for easier and safer surgery. The measurement was performed on the axial planes of 242 cranial computerized tomography (CT) scans and 27 adult Turkish skulls of both sexes. The length of the ACP, width of the ACP at its base, the angle formed by the apical angle of the ACP triangle and the orientation of the ACP defined according to the sagittal midline were examined. In the Turkish skulls, the length and width of the ACP were similar to previous studies. Our study was the first to measure the angle and orientation of the ACP. The mean angle was $39.67 \pm 12.64$ (16.6-89.5) and 135 posterior $(55 \%)$ and 107 medial (45\%) orientations. Surgical complications can be avoided by pre-operative radiological planning using axial CT scans and by determining whether the morphology is Type 2 (long, narrow, acute-angled), which requires total resection.

KEY WORDS: Anterior clinoid process; Morphometry; Skull base surgery.

\section{INTRODUCTION}

The anterior clinoid process (ACP) is located at the medial end of the lesser wing of the sphenoid bone and forms the lateral wall of the intracranial end of the optic canal (Inoue et al., 1990). The anterior clinoidectomy technique is of vital importance in the treatment of aneurysms involving the paraclinoid region (Yasargil et al., 1977; Heros et al., 1983; Dolenc, 1985; Nutik, 1988; Dolenc, 1999) and the upper basilar artery (Dolenc et al., 1987; Day et al., 1994).

The necessity of ACP removal has been emphasized previously in descriptions of surgical treatment of the internal carotid artery (ICA), the ophthalmic artery and large aneurysms (Ohmoto et al., 1991; Takahashi

et al., 2004).

Anterior clinoidectomy provides improved exposure of structures in and around the optic nerve, ICA and optic canal. It also enhances mobilization of the intracranial ICA and optic nerve with less brain retraction (Matsuyama et al., 1997; Seoane et al., 1998; Sato et al., 2001).

Intradural and extradural techniques have been described in detail by many authors (Dolenc, 1985, 1994; Yonekawa et al., 1997). The extradural approach to the ACP, first described by Dolenc $(1985 ; 1994)$, can also be used in the approach to the cavernous sinus, clinoidal space and orbital apex.

The purpose of this study was to quantify, with direct measurement, the length and width of the $\mathrm{ACP}$ together with the angles formed by the apex of the ACP triangle (Fig. 1), including its direction in adult skulls, and in axial cranial CT images. We grouped the results into two types. We preoperatively searched for the two types of ACP to determine the need for clinoidectomy and determined that it is necessary in one group, but not in the other.

* Department of Neurosurgery, Dr. Lutfi Kirdar Kartal Training and Research Hospital, Istanbul, Turkey.

** Department of Neurosurgery, Fatih Sultan Mehmet Training and Research Hospital, Istanbul, Turkey.

**** Department of Anatomy, Istanbul University, Istanbul School of Medicine, Istanbul, Turkey.

***** Department of Radiology, Sonomed Tibbi Goruntuleme Merkezi, Istanbul, Turkey. 


\section{MATERIAL AND METHOD}

The CT measurements were obtained from 121 Turkish adult heads ( 242 sides) without bilateral bone erosion of the clinoid process using a Siemens SOMATOM Sensation. The study was conducted on 64 female $(52.9 \%)$ and 57 male adults $(47.1 \%)$ whose ages ranged between 18-84 years (mean 43.04 16.65 ) and direct anatomic measurements were performed in 27 adult Turkish skulls of unknown age of both sexes collected from the Department of Anatomy, Faculty of Medicine, University of Istanbul, Turkey using standard calipers and goniometry. Metrical parameters are as described by Lee et al. (2013). Most sides displayed bony erosion and could not be measured bilaterally. Four heads were measured bilaterally for length, width and angles. For eight heads, only the right-sides were measured for length and width and for 15 heads, only the left-sides were measured for length and width. Only 9 right-sided angles and 14 left-sided angles were measured in the skulls.

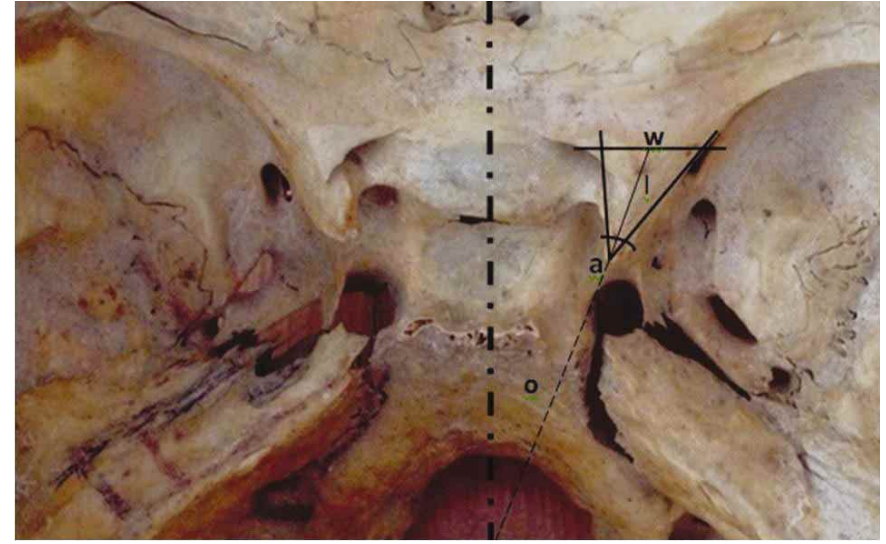

Fig. 1. Description of ACP triangle; "w" width, "l" length "a" angle and "o" orientation. The base of the triangle is formed by the width of ACP which is formed by drawing a horizontal line at ACP's medial point at its thickest edge (base) adjacent to emergence of the optic nerve intracranially connecting lateral ending point of $\mathrm{ACP}$ at the lesser wing of sphenoid bone. The apex of the triangle is the apical point of ACP. The line drawn tangent to the medial side of ACP and the line drawn tangent to the lateral side of ACP are the other margins of the triangle. The ACP tip orientation is described according to apex of the triangle heading towards posterior (parallel to midline sagittal axis) or towards medial (crossing midline sagittal axis)
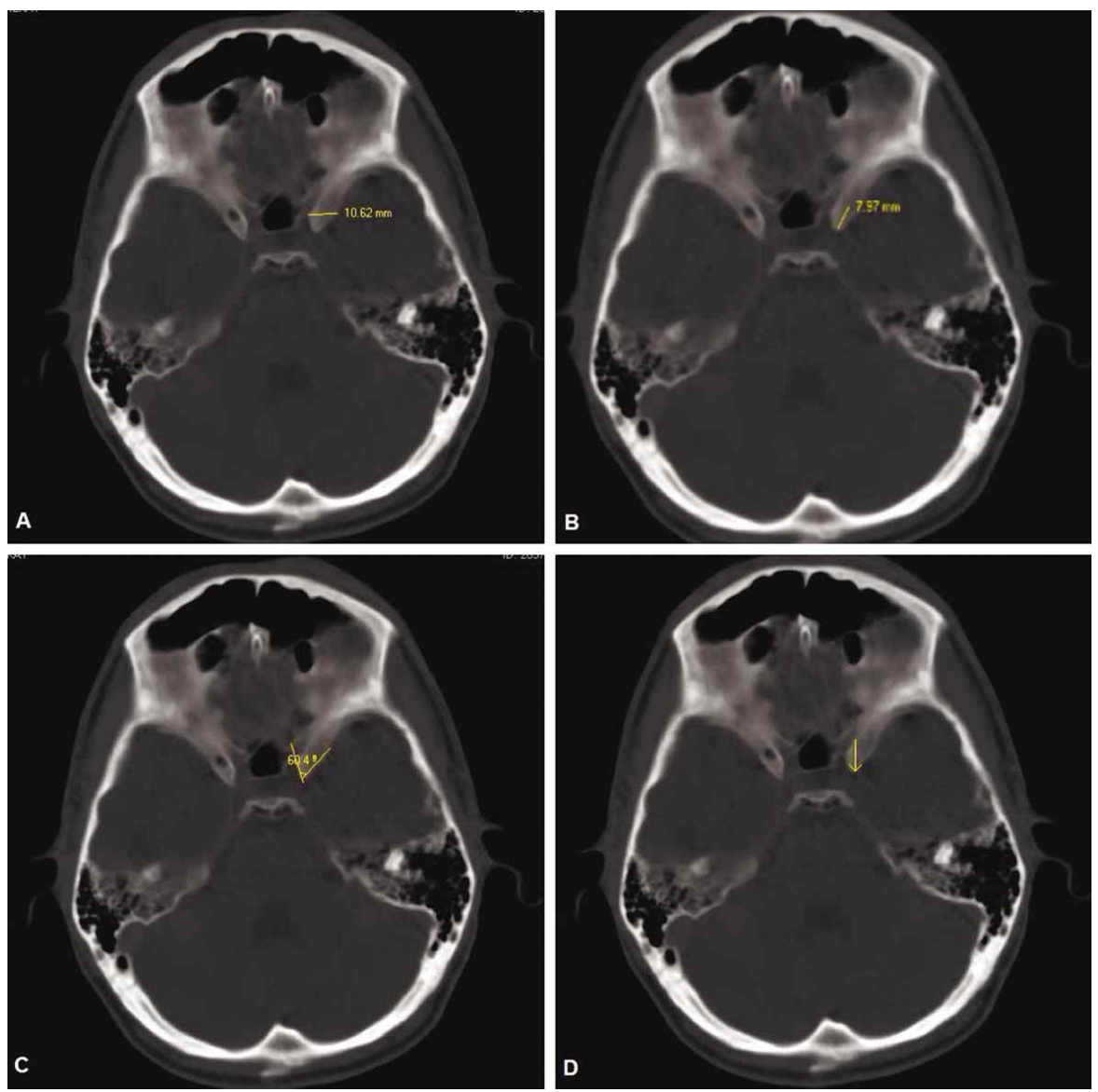

The perpendicular length (height), basal width and angle of the ACP and its direction were measured in both groups (Fig. 1). The angle of the ACP was calculated using the apical angle of the ACP triangle. The basal margin is formed by the anterior cranial fossa, the lateral margin by the (tangent line) lateral side of the lesser wing of the sphenoid and the medial margin by the (tangent line) intracranial end of the lateral side of the optic canal (Fig. 1). The direction of the ACP, based on apical tip orientation, was classed as posterior, with a direction parallel to the sagittal plane, or medial, with a direction crossing the sagittal plane midline (Figs. 1 and 2).

Fig. 2. Axial CT scan showing ACP Type 1 which is prone to easier surgical approach; A) width (wide), B) length (short), C) angle (wide-angled), D) orientation (posterior). 


\section{RESULTS}

CT measurements were obtained from 121 Turkish adult heads (242 sides) and anatomic measurements were obtained from 27 adult Turkish skulls by a radiologist (BTE), an anatomist (AK) and a neurosurgeon (AC). The CT measurements and anatomic measurements were evaluated separately and compared statistically.

Sex and age were not defined in the skulls, but were recorded on $\mathrm{CT}$ scans. CT measurements were performed on 64 female $(52.9 \%)$ and 57 male adults $(47.1 \%)$ whose ages ranged between 18-84 years (mean 43.04 \pm 16.65 ).

CT group: The right-sided measurements of the length, width, and angle of the ACP were $10.62 \pm 3.52 \mathrm{~mm}$, $8.12 \pm 1.78 \mathrm{~mm}$, and $39.99^{\circ} \pm 12.9$, respectively. The left-sided measurements of the length, width and angle of the ACP were $10.82 \pm 3.18 \mathrm{~mm}, 7.97 \pm 1.71 \mathrm{~mm}$, and $39.36^{\circ} \pm 12.43$, respectively. The right and left-sided measurements were not significantly different $(\mathrm{p}>0.05)$ (Table I).

Dry skull group: The right-sided measurements of the length, width and angle of the ACP were 10.90 \pm 3.76 $\mathrm{mm}, 10.53 \pm 1.83 \mathrm{~mm}$, and $44.46^{\circ} \pm 8.46$, respectively. The left-sided measurements of the length, width, and angle of the ACP were $13.46 \pm 3.41 \mathrm{~mm}, 11.17 \pm 2.49 \mathrm{~mm}$, and $39.5^{\circ} \pm 8.81$, respectively. The right and left-sided measurements were not significantly different $(\mathrm{p}>0.05)$ (Table I).

The right-sided CT measurements and right-sided skull measurements were compared. There were no statistically significant differences between the groups with regard to length and angle ( $\mathrm{p}>0.05)$; however, dry skull width values were significantly higher than the CT values $(\mathrm{p}<0.01)$ (Table I).

The left-sided CT measurements and left-sided skull measurements were compared. There were no statistically significant differences between the groups with regard to width and angle ( $p>0.05)$; however, dry skull length values were significantly higher than the CT values $(\mathrm{p}<0.01)$ (Table I).

Right and left-sided CT measurements were summed and the mean and standard deviation were calculated (Table II).

Comparison of the combined values (right and left sides) of the CT and skull measurements showed no significant differences between the groups with regard to angles ( $p>0.05$ ); however, the length and width values were significantly higher for the dry skulls compared to the CT group $(\mathrm{p}<0.01)$ (Table III).

CT group: The length of the ACP ranged between 4.74 and $20 \mathrm{~mm}$ (mean $10.74 \pm 3.35 \mathrm{~mm}$ ), with most being between 8.9 and $11.74 \mathrm{~mm}$. The width of the ACP ranged between 4.76 and $13.4 \mathrm{~mm}$ (mean $8.05 \pm 1.74 \mathrm{~mm}$ ), with most being between 7.23 and $8.73 \mathrm{~mm}$. The angle of the ACP ranged between 16.6 and $89.5^{\circ}$ (mean $39.67^{\circ} \pm 12.64$ ), with most being between 33.4 and $43.4^{\circ}$ (Fig. 1).

Dry skull group: The length of the ACP ranged between 5 and $19.5 \mathrm{~mm}$ (mean $12.5 \pm 3.71 \mathrm{~mm}$ ), with most being between $10 \mathrm{~mm}$ and $13.5 \mathrm{~mm}$. The width of the ACP ranged between 6.5 and $18 \mathrm{~mm}$ (mean $10.93 \pm 2.25 \mathrm{~mm}$ ), with most being between 10 and $11.5 \mathrm{~mm}$. The angle of the ACP ranged between 20 and $58^{\circ}$ (mean $42.09^{\circ} \pm 9.20$ ), with most being between 38 and $45^{\circ}$ (Fig. 2).

We classified the direction of the ACP as posterior when the orientation was towards the paramedian sagittal plane (axis), and as medial when the orientation was towards the median axis in the anteroposterior direction crossing the midline (Fig. 1e). There were $135(55 \%)$ bones with a posterior direction and $107(45 \%)$ with a medial direction (Table IV).

ACPs shorter than $10.5 \mathrm{~mm}$ this were classified as short and those longer than $10.5 \mathrm{~mm}$ were classified as long.

ACPs narrower than $8.14 \mathrm{~mm}$ were classified as narrow and those wider than $8.14 \mathrm{~mm}$ were classified as wide.

ACPs with angles more acute than $39.5^{\circ}$ were classified as narrow-angled and those with angles more obtuse than $39.5^{\circ}$ were classified as wide-angled (Table IV).

Using these measurements we classified ACPs into three main groups: two main types and a third that included ACPs inconsistent with the two main types. Type I ACPs are short, wide, and wide-angled, which should allow for easier surgical approaches (Fig. 3a-b-c-d). Type II ACPs are long, narrow, and narrow-angled, which require more challenging surgical techniques.

In our study 40 (16.5\%) were Type I ACPs, 43 (17.8 $\%)$ were Type II ACPS, and 159 (65.7\%) were classified as Type III ACPs (Table IV). 

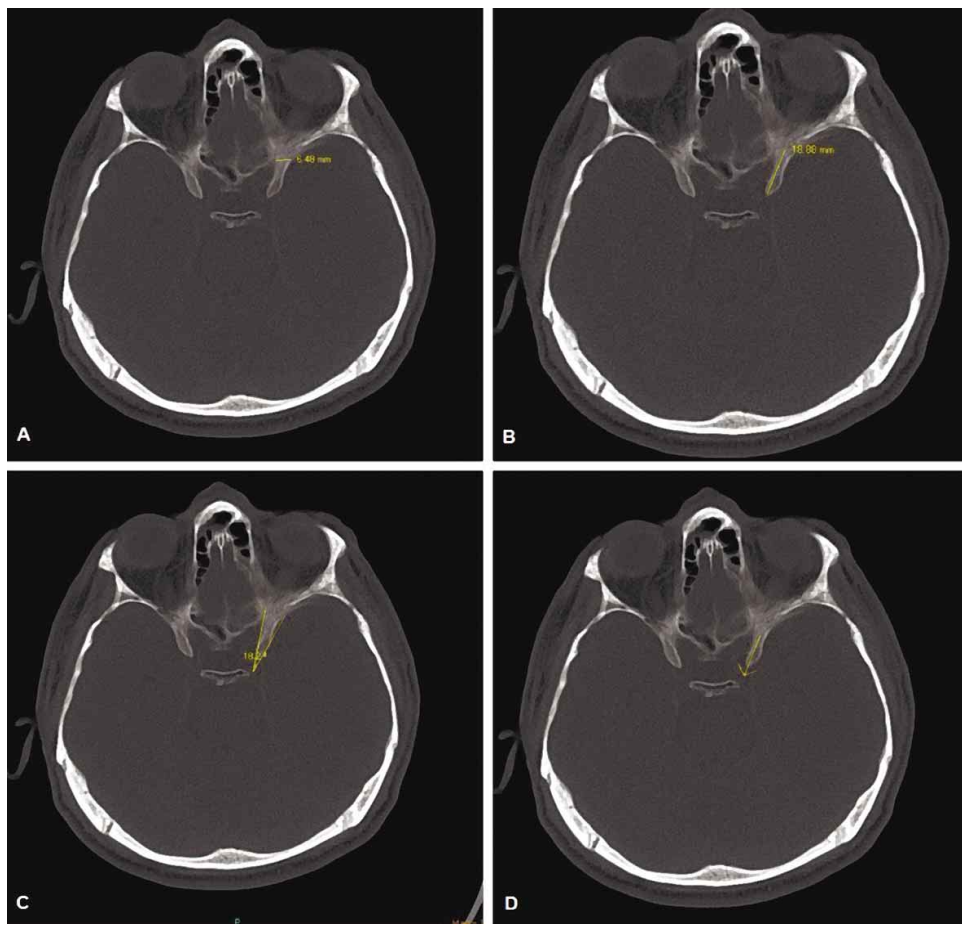

Fig. 3. Axial CT scan showing ACP Type 2 which is an obstacle for surgery; A) width (narrow), B) length (long), C) angle (narrow-angled), D) orientation (medial).

\section{DISCUSSION}

The ACP is a bony projection of the lesser sphenoid wing and is connected to the sphenoid bone by two extensions. The superior part forms the roof of the optic canal, and the inferior part forms its lateral wall (De Jesús, 1997). It is connected to the planum sphenoidale superiorly and to the lesser wing inferiorly (De Jesús). Lee et al. (1997), examined Korean skulls and found that the mean ACP length and width were $9.18 \pm 1.55$ and $9.63 \pm 1.49 \mathrm{~mm}$, respectively. Lee et al., found in their study of fresh cadavers that the ACP height was shorter and the base wider $(7.61 \pm 1.50$ and $10.82 \pm 1.82$ $\mathrm{mm}$, respectively) compared to a previous study. Andaluz et al. (2006), reported relatively small values for both height $(8.67 \pm 2.63 \mathrm{~mm})$ and width $(6.57 \pm 1.68 \mathrm{~mm})$. Hunnargi et al. (2008), reported in their dry skull study, differences between South Indian, Nepalese and Korean ACP dimensions on both the right and left side. They found that the average length of the right ACP was $10.68 \pm 1.90 \mathrm{~mm}$ and that of the left

Table I. In CT and cadaver group comparison of right and left sides.

\begin{tabular}{llrrrrr}
\hline & \multicolumn{2}{c}{ Right } & \multicolumn{2}{c}{ Left } & \\
& & \multicolumn{1}{c}{ Min-Max } & \multicolumn{1}{c}{ Mean \pm SD } & \multicolumn{1}{c}{ Min-Max } & \multicolumn{1}{c}{ Mean \pm SD } & p \\
\hline CT & Length & $4.98-20.0$ & $10.66 \pm 3.52$ & $4.76-18.0$ & $10.82 \pm 3.18$ & $\mathbf{0 . 7 1 6}$ \\
& Width & $4.8-13.23$ & $8.12 \pm 1.78$ & $4.76-13.4$ & $7.97 \pm 1.71$ & $\mathbf{0 . 4 9 0}$ \\
Cadaver & Angle & $16.6-76.2$ & $39.99 \pm 12.9$ & $18.8-89.5$ & $39.36 \pm 12.43$ & $\mathbf{0 . 7 0 1}$ \\
& Length & $5.0-19.5$ & $10.90 \pm 3.76$ & $9.0-19.0$ & $13.46 \pm 3.41$ & $\mathbf{0 . 0 5 7}$ \\
& Width & $8.0-13.5$ & $10.53 \pm 1.83$ & $6.5-18.0$ & $11.17 \pm 2.49$ & $\mathbf{0 . 4 4 6}$ \\
& Angle & $28-0-55.0$ & $44.46 \pm 8.46$ & $20.0-50.0$ & $\mathrm{~s} 39.5 \pm 8.81$ & $\mathbf{0 . 1 2 7}$ \\
\hline
\end{tabular}

Right-sided cadaveric width values were statistically significantly higher when compared to CT values ( $\mathrm{p}<0.01)$. Left-sided cadaveric length values were statistically significantly higher when compared to CT values $(\mathrm{p}<0.01)$.

Table II. In CT group results of right and left sides of ACP measurements together and values under and above the mean.

\begin{tabular}{llcccc}
\hline \multirow{2}{*}{ Length } & Short & N & \% & Min-Max & Mean \pm SD \\
& Long & 116 & 47.9 & $4.76-20$ & $10.74 \pm 3.35$ \\
\multirow{2}{*}{ Width } & Narrow & 128 & 52.1 & & \\
& Wide & 114 & 47.1 & $4.76-13.4$ & $8.05 \pm 1.74$ \\
& Acute & 130 & 53.7 & $16.6-89.5$ & $39.67 \pm 12.64$ \\
& Obtuse & 112 & 46.3 & & \\
\hline
\end{tabular}

Table III. Comparison of results of CT group and cadaveric group for length, width and angle of ACP bilaterally.

\begin{tabular}{lccc}
\hline & CT Mean \pm SD & Cadaver Mean \pm SD & \multicolumn{1}{c}{ P } \\
\hline Length & $10.74 \pm 3.35$ & $12.50 \pm 3.71$ & $\mathbf{0 . 0 0 6}^{* *}$ \\
Width & $8.04 \pm 1.74$ & $10.93 \pm 2.25$ & $\mathbf{0 . 0 0 1 * *}$ \\
Angle & $39.67 \pm 12.64$ & $42.09 \pm 9.20$ & $\mathbf{0 . 1 9 0}$ \\
\hline
\end{tabular}

Table IV. Range of Direction and Types (All groups together).

\begin{tabular}{llrr}
\hline & & $\mathbf{n}$ & $\mathbf{\%}$ \\
\hline Direction & Posterior & 135 & 55 \\
& Medial & 107 & 45 \\
Types & Type I & 11 & 4 \\
& Type II & 16 & 5.9 \\
& Others & 246 & 90.1 \\
\hline
\end{tabular}


was $9.96 \pm 1.71 \mathrm{~mm}$. Although the left ACP was shorter than the right, the difference was not significant. Similar results were found by Hayashi (2004) and by Gupta et al. (2005). Both the right and left ACPs were longer in South Indian skulls than Nepalese and Korean skulls (Gupta et al.; Hunnargi et $a l . ;$ Lee $e t a l$. .). The basal width of the ACP in South Indian skulls was slightly greater on the right compared to the left, but in Nepalese skulls, the converse was true (Gupta et al.). This was not the case in Indian and Korean skulls. Compared to Nepalese and Korean skulls, the basal width of the Indian skulls was slightly greater.

In our study of dry skulls, the right sides were shorter and the left sides were wider, as in the Nepalese skulls, but unlike the South Indian skulls; however, the right- and leftside measurements did not differ significantly for any parameter.

Yang et al. (2011), in their study of direct anatomic measurements and CT-aided three-dimensional reconstruction scans performed on 10 (20 sides) formalintreated cadaveric specimens and 15 (30 sides) adult skulls to analyze the optic canal and its anatomic relationship with adjacent structures, including the ACP, reported an average ACP length of $9.87 \pm 1.34 \mathrm{~mm}$ and average width of $11.66 \pm$ $2.35 \mathrm{~mm}$. The authors concluded that secondary injury to the optic nerve and direct injury to the ICA and ophthalmic artery might occur during surgical procedures due to variation in the ACP.
Many CT measurements concerning the pneumatization of the anterior clinoid process can be performed (Abuzayed et al., 2010). Cheng et al. (2013), measured the length and thickness of the ACP and the distance between the apex of the ACP and the sagittal midline in multiplanar reformed CT images of 204 sides from 102 individuals and sorted the ACP into four types: 0 , I, II, and III, based on Hunnargi's classification.

In our study, the right-side measurements of the length, width, and angle of the ACP by CT were $10.66 \pm 3.52$ $\mathrm{mm}, 8.12 \pm 1.78 \mathrm{~mm}$, and $39.99 \pm 12.9^{\circ}$, respectively. The leftside measurements of the length, width, and angle of the ACP were $10.82 \pm 3 \mathrm{~mm}, 7.97 \pm 1.71 \mathrm{~mm}$, and $39.36 \pm 12.43^{\circ}$, respectively. The right and left-side measurements in the CT group were compared; no statistically significant differences were identified ( $p>0.05$ ) (Table I).

In conclusion the anatomical structure of the ACP, including the apical angle of the ACP triangle and its orientation in either a posterior or medial direction, are reported in this study and may serve as guides for planning clinoidectomy and aneurysm clipping. Pre-operative radiological planning by reviewing axial CT scans can help to avoid surgical complications. Attention must be paid to Type II (long, narrow, acute-angled) ACPs, which require more challenging surgical techniques and more complicated neurosurgical approaches or osteotomies using skull base techniques.

CECEN, A.; CELIKOGLU, E.; IS, M.; CETI NER KALE, A. \& TORUM EROGLU, B. Medición preoperatoria de la morfometría y los ángulos del proceso clinoide anterior (PCA) para la cirugía de aneurisma. Int. J. Morphol., 34(4):1333-1338, 2016.

RESUMEN: El proceso clinoide anterior (PCA) está próximo a estructuras vitales, como el nervio óptico, la arteria carótida interna y la arteria oftálmica, por tanto el estudio de su anatomía es importante en la orientación y la definición de la cirugía de base de cráneo. Se estudió la estructura anatómica de la PCA, incluyendo el ángulo formado por el vértice del triángulo PCA, y su orientación, para proporcionar información para una cirugía más fácil y más segura. La medición se realizó en los planos axiales de 242 exploraciones craneales de tomografía computarizada (TC) y 27 cráneos de individuos adultos turcos de ambos sexos. Se examinó la longitud del PCA, el ancho del PCA en su base, el ángulo formado por el ángulo apical del triángulo PCA y la orientación del PCA definido de acuerdo con la línea mediana sagital. En cráneos turcos, la longitud y el ancho del PCA fueron similares a estudios anteriores. Nuestro estudio fue el primero en medir el ángulo y la orientación del PCA. El ángulo promedio fue de 39,67 $\pm 12,64$ (16,6 a 89,5) y, la orientación fue posterior en 135 cráneos $(55 \%)$ y medial en 107 cráneos (45\%). Las complicaciones quirúrgicas pueden evitarse mediante la planificación radiológica preoperatoria através de cortes axiales de tomografía computarizada y determinando si la morfología del PCA es de tipo 2 (larga, estrecha y aguda en ángulo recto), lo que requiere la resección total.

PALABRAS CLAVE: Proceso clinoide anterior; Morfometría; Cirugía de base de cráneo.

\section{REFERENCES}

Abuzayed, B.; Tanriover, N.; Biceroglu, H.; Yuksel, O.; Tanriover, O.; Albayram, S. \& Akar, Z. Pneumatization degree of the anterior clinoid process: a new classification. Neurosurg. Rev., 33(3):367-73, 2010.
Andaluz, N.; Beretta, F.; Bernucci, C.; Keller, J. T. \& Zuccarello, M. Evidence for the improved exposure of the ophthalmic segment of the internal carotid artery after anterior clinoidectomy: morphometric analysis. Acta Neurochir. (Wien), 148(9):971-5, 2006. 
Cheng, Y.; Wang, C.; Yang, F.; Duan, Y.; Zhang, S. \& Wang, J. Anterior clinoid process and the surrounding structures. $J$. Craniofac. Surg., 24(6):2098-102, 2013.

Day, J. D.; Giannotta, S. L. \& Fukushima, T. Extradural temporopolar approach to lesions of the upper basilar artery and infrachiasmatic region. J. Neurosurg., 81(2):230-5, 1994.

De Jesús, O. The clinoidal space: anatomical review and surgical implications. Acta Neurochir. (Wien), 139(4):361-5, 1997.

Dolenc, V. V. A combined epi- and subdural direct approach to carotid-ophthalmic artery aneurysms. J. Neurosurg., 62(5):66772, 1985 .

Dolenc, V. V.; Skrap, M.; Sustersic, J.; Skrbec, M. \& Morina, A. A transcavernous-transsellar approach to the basilar tip aneurysms. Br. J. Neurosurg., 1(2):251-9, 1987.

Dolenc, V. V. Frontotemporal epidural approach to trigeminal neurinomas. Acta Neurochir. (Wien), 130(1-4):55-65, 1994.

Dolenc, V. V. A combined transorbital-transclinoid and transsylvian approach to carotid-ophthalmic aneurysms without retraction of the brain. Acta Neurochir. Suppl., 72:89-97, 1999.

Gupta, N.; Ray, B. \& Ghosh, S. A study on anterior clinoid process and optic strut with emphasis on variations of caroticoclinoid foramen. Nepal Med. Coll. J., 7(2):141-4, 2005.

Hayashi, N.; Masuoka, T.; Tomita, T.; Sato, H.; Ohtani, O. \& Endo, S. Surgical anatomy and efficient modification of procedures for selective extradural anterior clinoidectomy. Minim. Invasive Neurosurg., 47(6):355-8, 2004.

Heros, R. C.; Nelson, P. B.; Ojemann, R. G.; Crowell, R. M. \& DeBrun, G. Large and giant paraclinoid aneurysms: surgical techniques, complications, and results. Neurosurgery, 12(2):153-63, 1983.

Hunnargi, S.; Ray, B.; Pai, S. R. \& Siddaraju, K. S. Metrical and non-metrical study of anterior clinoid process in South Indian adult skulls. Surg. Radiol. Anat., 30(5):423-8, 2008.

Inoue, T.; Rhoton, A. L. Jr.; Theele, D. \& Barry, M. E. Surgical approaches to the cavernous sinus: a microsurgical study. Neurosurgery, 26(6):903-32, 1990.

Lee, H. Y.; Chung, I. H.; Choi, B. Y. \& Lee, K. S. Anterior clinoid process and optic strut in Koreans. Yonsei Med. J., 38(3):1514, 1997.

Lee, H. W.; Park, H. S.; Yoo, K. S.; Kim, K. U. \& Song, Y. J. Measurement of critical structures around paraclinoidal area: A Cadaveric morphometric study. J. Korean Neurosurg. Soc., 54(1):14-8, 2013.

Matsuyama, T.; Shimomura, T.; Okumura, Y. \& Sakaki, T. Mobilization of the internal carotid artery for basilar artery aneurysm surgery. Technical note. J. Neurosurg., 86(2):2946, 1997.

Nutik, S. L. Removal of the anterior clinoid process for exposure of the proximal intracranial carotid artery. J. Neurosurg., 69(4):529-34, 1988.

Ohmoto, T.; Nagao, S.; Mino, S.; Ito, T.; Honma, Y. \& Fujiwara, T. Exposure of the intracavernous carotid artery in aneurysm surgery. Neurosurgery, 28(2):317-23, 1991.

Sato, S.; Sato, M.; Oizumi, T.; Nishizawa, M.; Ishikawa, M.; Inamasu, G. \& Kawase, T. Removal of anterior clinoid process for basilar tip aneurysm: clinical and cadaveric analysis. Neurol. Res., 23(4):298-303, 2001.

Seoane, E.; Rhoton, A. L. Jr. \& de Oliveira, E. Microsurgical anatomy of the dural collar (carotid collar) and rings around the clinoid segment of the internal carotid artery. Neurosurgery, 42(4):869-84, 1998.

Takahashi, J. A.; Kawarazaki, A. \& Hashimoto, N. Intradural enbloc removal of the anterior clinoid process. Acta Neurochir. (Wien), 146(5):505-9, 2004.

Yang, J.; Wu, X.; Liu, J. X.; Lin, R. S.; Li, Z. Q.; Ma, S. C.; Qi, J. F.; Cun, E. H. \& Yu, C. J. Microanatomic and three-dimensional reconstruction study of lateral wall and related structures of optic canal. Zhonghua Yi Xue Za Zhi, 91(5):322-6, 2011.

Yasargil, M. G.; Gasser, J. C.; Hodosh, R. M. \& Rankin, T. V. Carotid-ophthalmic aneurysms: direct microsurgical approach. Surg. Neurol., 8(3):155-65, 1977.

Yonekawa, Y.; Ogata, N.; Imhof, H. G.; Olivecrona, M.; Strommer, K.; Kwak, T. E.; Roth, P. \& Groscurth, P. Selective extradural anterior clinoidectomy for supra- and parasellar processes. Technical note. J. Neurosurg., 87(4):636-42, 1997.

Correspondence to:

Merih IS, M.D.

Department of Neurosurgery

Fatih Sultan Mehmet Training and Research Hospital, E5 Karayolu uzeri Icerenkoy/Atasehir

Istanbul

TURKEY

Email: merihis@yahoo.com
merihis@gmail.com

Received: 27-02-2016

Accepted: 02-09-2016 